\title{
Wireless Detector for Lung Sound Disorder Based on DSP TMS320C6416T Module
}

\author{
Nyayu Latifah Husni ${ }^{1}{ }^{*}$ Arganda Meranda ${ }^{1}$ Destra Andika Pratama ${ }^{1}$ Ekawati \\ Prihatini ${ }^{1}$ Selamat Muslimin ${ }^{1}$ Ade Silvia Handayani ${ }^{1}$ \\ ${ }^{1}$ State Polytechnic of Sriwijaya, Electrical Engineering, Palembang, Indonesia. \\ ${ }^{*}$ Corresponding author. Email: nyayu latifah@polsri.ac.id
}

\begin{abstract}
Lung sound disorder can be one of the signs that indicate the human respiratory problems. The conventional stethoscope can be used to determine the imperfection of the lung; however, it only depends on the ability of hearing. When someone's has problem of hearing, they cannot use this device. In addition, the sound of the conventional stethoscope sometimes cannot be heard clearly. This paper proposed a digital stethoscope that can be visualized. This research focuses on the ability of the system to transfer the signal sound into digital display that can be monitored in mobile phone. In this research, the recorded data of lung sound is stored in the PC using the 'record sound' program. The data was then analyzed using the waveform graph time-domain, FFT Power Spectrum, STFT Spectrogram and Wavelet Scalogram. For the communication between DSP TMS320C6416T and LabView 2012, a LabView 8.6 is used. In this research, the authors also use NodeMCU ESP826 as the Access Point of the communication. On the other hand, for generating the communication between the LabView and NodeMCU, the author used VISA (Virtual Instrument Software Architecture) of LabView 2012. From experiment to 6 patients, it can be found that the proposed device can run well and can visualize the normal lung with the frequency of $300 \mathrm{~Hz}-600 \mathrm{~Hz}$.
\end{abstract}

\section{Keywords: Lung Sound, Detector, Stethoscope}

\section{INTRODUCTION}

The lungs are one of the organs in the body that play an important role in running the human respiratory system. When air reaches the lungs, there will be an exchange of oxygen from outside of the body with the carbon dioxide from the blood. If the lungs experience disorders or abnormalities that will have a negative impact on the performance of the respiratory system, the respiratory process will also be disrupted that can lead to the death [1].

The performance of lung function in our bodies can be decreased due to some diseases. These diseases can be caused by several factors, such as genetic factors, diet, air pollution, too many inhalations of cigarette smoke, and bacterial or viral infections. Several examples of lung diseases that can be found are asthma, lung cancer, lung infections, and chronic obstructive pulmonary disease (COPD) [2].

One way to prevent lung diseases is to recognize the symptoms that often occur in the lungs. A monitoring tool that is often used is a stethoscope. Using a stethoscope, a pulmonologist can see the symptoms that occur in the patient's lungs. In this way, the doctor can determine the condition of the patient's lungs.
Auscultation is the technique that is used to listen the sounds inside a person's body, such as breathing sounds in humans (in this case the lungs). The doctors can determine the patient's condition by using this technique. However, the technique of auscultation using a conventional stethoscope has many limitations and drawbacks, i.e., it is a subjective process in which the results depend on a person's hearing ability [3].

To reduce the limitations of auscultation techniques, a wireless detector was proposed in this research. This device can convert the sound signal generated by the lungs into a digital signal that can be displayed in PCs and mobile phones. Therefore, this device can make easier the user to recognize the sound patterns produced by the lungs by analyzing the displayed signals. This device can also simplify the decision process of the doctors in determining the sickness of the patients. In addition, due to this device can be monitored wirelessly, it can be monitored in further distance [4]-[9] so that the doctors do not need to get closed to the patients. Therefore, it is safe to be used by the doctors in the COVID 19 era nowadays. This project is the continuing of the authors' last project [10]. 


\section{LITERATURE REVIEW}

\subsection{Lung Sounds}

Lung sounds are part of the breathing sound (respiratory sound). Breathing sounds include sounds in the mouth and trachea, while lung sounds occur around the chest (chest wall). In the human lungs there is a sound that occurs due to the turbulence of the air when air enters the respiratory tract during the inhalation process. The difference in the width of the airways in the respiratory system causes air to flow from the wide air duct to the narrower channel or vice versa, resulting in turbulence.

The breathing process is divided into two parts, namely the inspiration process and the expiration process. The process of inspiration is the process when living things breathe air into the lungs, while the process of expiration is the process when living things remove air from the lungs. In the process of inspiration, the sound of the lungs that is heard will be stronger than in the expiration process. This is because the air turbulence during the inspiration process is stronger than the expiration process [11].

Lung sounds are divided into three categories, namely normal lung sounds, abnormal lung sounds, and adventitious sounds. There are 12 auscultation sites on the anterior chest and 14 sites on the posterior. Exhalation sounds can be divided into several categories as in Table 1.

Table 1 Types of Lung Sounds

\begin{tabular}{|c|c|c|}
\hline Normal & Abnormal & Adventious \\
\hline tracheal & absent/decreased & crackles \\
vesiculer & Harsh Vesicular & wheeze \\
bronchial & & rhonchi \\
bronchovesi-cular & & stidor \\
& & pleural rub \\
\hline
\end{tabular}

\subsection{Auscultation Process}

Auscultation is a technique for listening to sounds from the body. The auscultation process is important because it requires an effective and clinical technique to evaluate a patient's respiratory function using a stethoscope. Lung auscultation is performed to detect basic breath sounds and additional breath sounds.

Auscultation should be carried out over the entire chest and back, including the axillary area. At the time of auscultation, it is better for the patient not to speak and not to breathe using the mouth, because one complete breath is required for each location. There were 12 auscultation sites on the anterior chest and 14 posterior sites. In general, there should be at least 6 locations anteriorly and 6 posteriorly to be heard.

\section{PROPOSED METHOD}

The stethoscope in this research is designed by using the conventional one that has been equipped with a condenser microphone in the diaphragm section. The sound signal that has been captured by the stethoscope will be amplified with a pre-amplifier.

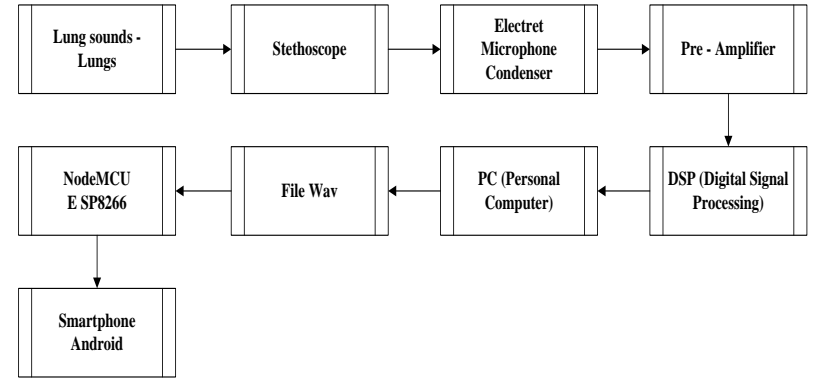

Figure 1 Block Diagram of proposed device
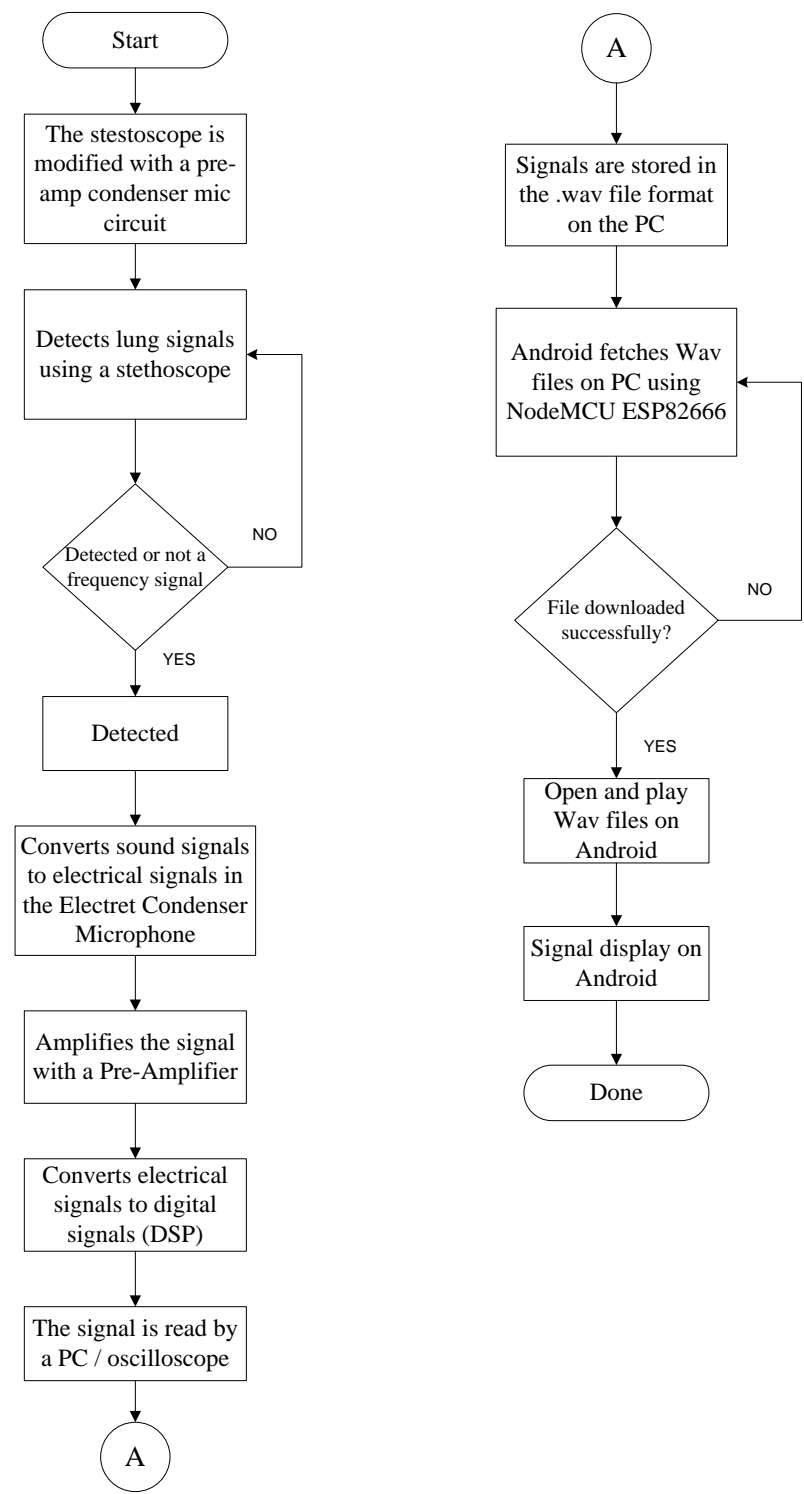

Figure 2 Flowchart of proposed device

This amplified signal will be filtered and converted to a digital signal in the Digital Signal Processing (DSP) unit. The digital signal will be displayed in a Personal Computer (PC) which stored the results of lung auscultation in .wav file. This .wav file can be transferred to mobile phones via NodeMCU ESP8266 module which acts as a communication medium. 
This module uses wifi communication which can let the user to analyze the results of the patient's lung voice recordings. The data can be stored in mobile phones, so that it can help the user (doctors) to analyze the patient's lung sound from different place. In this case the doctor does not need to analyze the patients in the examination room. The doctors need only to see the visualization that appears on the smart phones. The block diagram and the flowchart of the proposed device can be seen in Figure 1 and Figure 2.

\subsection{Circuit Schematic}

The circuit schematic of the proposed device can be seen in Figure 3. For a voltage source which is useful as a source of electricity to turn on the equipment components in proposed device, a power supply is needed.

The stethoscope in which the earpiece has been cut off will be connected to the electrets condenser microphone. The XLR cable electrets condenser microphone will be connected to the male XLR connector on the pre-amplifier due to this microphone requires $48 \mathrm{~V}$ phantom power via an ultragain mic100 tube type pre-amplifier. The pre-display on the TRS female connector cable is connected to the DSP that is used as the DSP line input. In order to be able to see the graphic display of the sound to be recorded the DSP line output, connect the jack cable. In the NodeMCU section, there is a micro USB which is connected to the USB port in the personal Computer (PC).

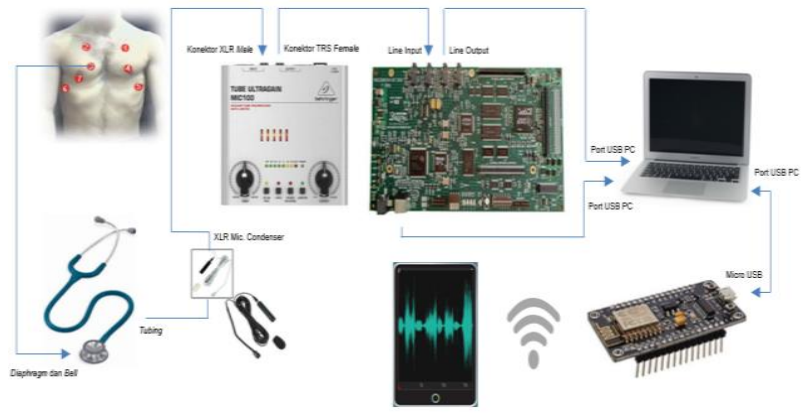

Figure 3 Schematic of Lung Sound Detection Series

\subsection{Mechanical Design}

Figures 4 below shows the mechanical design of the proposed of lung sound detector device that has been designed. The proposed device uses a rectangular acrylic material as its mechanical design. The top of the mechanical design is used as a pre-amplifier and NodeMCU holder, while the bottom is used as a DSP holder.

The proposed research used DSP TMS320C6416T as the digital signal processor and NodeMCU as wifi communication. The lung sounds that were captured by a stethoscope that had been equipped with an electret condenser microphone, were then amplified by the preamplifier, i.e. tube ultragain mic100. The pre-amplifier and the DSP used the balancing input connection as their connector.

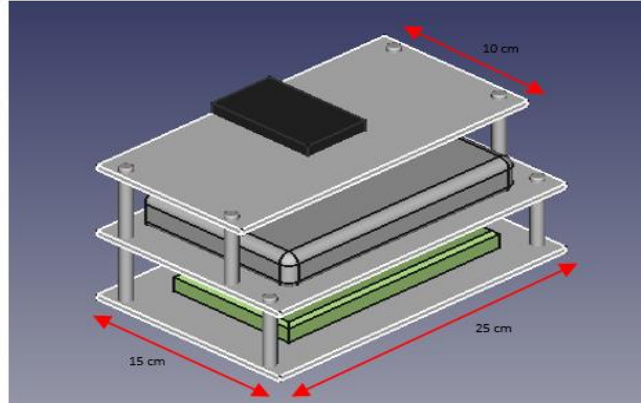

(a) Overall Mechanical Design

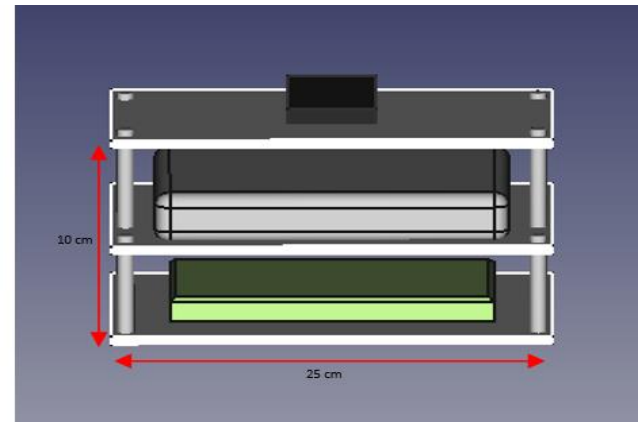

(b) Front View

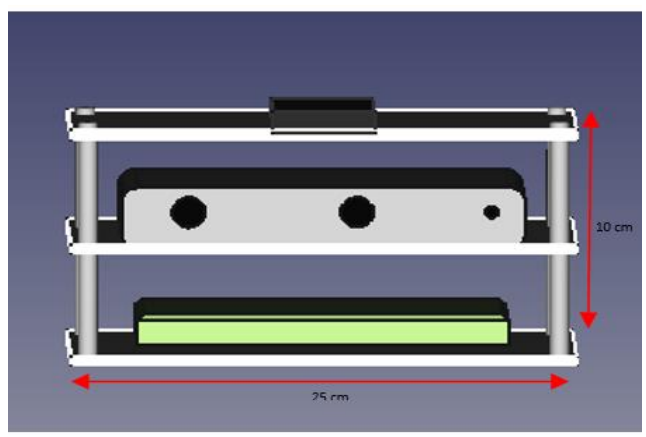

(c) Back View

Figure 4 Mechanical Design of proposed device

After the electrical signal was amplified by the preamplifier, the signal was then processed in the DSP unit that converted the signal into discrete data. To obtain discrete data, several steps were carried out, namely the sound signal was converted into an electrical signal using a transducer (to convert the sound signal into an analog electrical signal). This analog signal was fed to an analog filter in order to limit the frequency. After that, the analog signal will be converted through the ADC unit so that it can be converted into a digital signal. Then, the DSP received the digital signal and processed the digital data. After that, the lung auscultation results were stored in a Personal Computer (PC) in Wav file form. This .wav file was transferred to mobile phone via NodeMCU ESP8266 module as a communication medium. This module used wifi communication so that the data can be visualized in smart phones.

To perform lung sound analysis, a display in the form of a time-domain waveform graph, FFT Power Spectrum, STFT Spectogram and Wavelet Scalogram are used. LabView 8.6 software is used for the 
communication between the DSP TMS320C6416T and LabView 2012. The authors also use the advanced signal processing toolkit in making programs for lung sound analysis. For LabView communication with NodeMCU, the author also uses the VISA (Virtual Instrument Software Architecture) method in LabView 2012.

\section{RESULTS AND DISCUSSION}

The process of analyzing the normal lung sounds in this research is based on the duration of time and the pattern of the inspiratory and expiratory processes. On the other hand, the adventitious sounds are easier to be analyzed in the form of a spectrogram and a scalogram because it is used to find or take characteristics of the pulmonary sound signal.

\subsection{Retrieval of Data through Software}

The steps to operate the pulmonary sound abnormality detection from DSP TMS320C6416T to LabView 8.6 are as follows:

1. Make sure all components in the proposed device is in good condition and can be used by rechecking the equipment and cables connected to the appliance are correct.

2. Turn on the ultragain tube mic100 pre-amplifier and the DSP TMS320C6416T by connecting the cable to the power supply.

3. Then, connect the XLR Input cable to the stethoscope that has been equipped with an electret condenser microphone. Then, connect the XLR output cable on the pre-amplifier to the "line in" on the DSP TMS320C6416T. After that, connect the "line out" on the DSP to the PC (Personal Computer).

4. Then, connect the USB port to the PC, After that connect the LabView 8.6 software to the DSP TMS320C6416T.

5. When the DSP Module and software are connected, a signal graphic will be generated as shown in Figure 5

6. Next, place the modified stethoscope into the auscultation site on the anterior or posterior chest to detect the lung sounds.

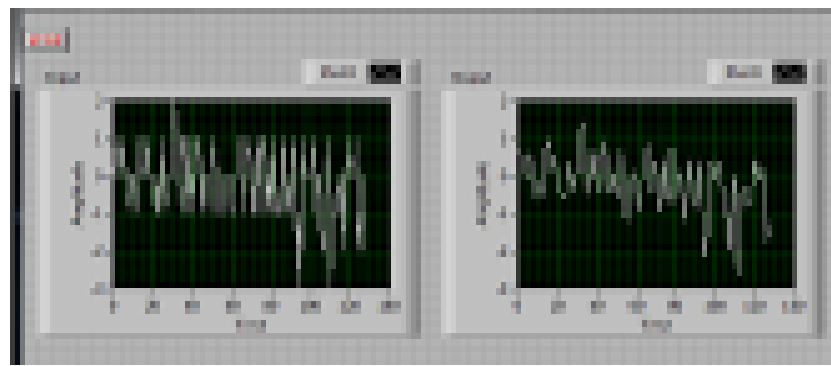

Figure 5 DSP Graph Display and Connected LabView Software

\subsection{Real-Time Data Retrieval Steps}

The steps for direct data collection are carried out directly on the person to be examined (patient), as follows:

1. Prepare all lung sound detection equipment that has been designed for testing.

2. Before carrying out the test, check the equipment that has been designed to be tested directly on the person to be examined.

3. Place the stethoscope on the tracheal, bronchial, bronchovesicular and vesicular parts of the person being examined.

4. Perform a direct examination of a person sitting upright and make sure that the stethoscope is positioned right on the part to be examined.

5. Save the lung sound record file and open the file using the block analysis program to see the lung sound frequency.

6. After completing the inspection, disconnect all cable connections and turn off all equipment connected to the power supply.

7. Finally, rearrange all cables and equipment neatly.

\subsection{Steps to Transfer. Wav Files to Smartphone}

The steps for transferring the results of the lung sound record in the form of a .wav file from a PC to a smart phone via NodeMCU which is set as a portable hotspot are as follows:

1. First, do the sharing settings for the folder where the .wav data results from the sound record by rightclicking on the folder to be shared. After that, select 'give access to', then select 'specific people', then select' 'everyone' and click' 'Add', then select 'Read/Write on the permissions level' and click 'share' then done.

2. Next, connect the micro USB connected from NodeMCU to the USB port on the PC.

3. If the USB port is connected, a display on the LCD "Lung Sound Detection" (in Bahasa 'Deteksi Suara Paru-Paru') will appear, which indicates that NodeMCU and PC are connected, it can be seen in Figure 6.

4. Then, enter the COM NodeMCU input on the VISA resource name block which is the serial port communication.

5. Run the program on LabView in order to control NodeMCU directly from LabView.

6. Activate NodeMCU portable hotspot from LabView.

7. Make sure the portable hotspot is active by looking at the display on the LCD and the wifi feature on the smartphone or PC.

8. Then, connect the wifi smartphone and PC to the NodeMCU portable hotspot.

9. If you have connected, then access the .wav file using the file manager application on the smart phones by adding a LAN (Local Area Network) remote device and match the IP address on the laptop that is connected to the NodeMCU access 
point (hotspot), (in this experiment The IP address on NodeMCU is 192.168.4.1).

10. Then, open and play the .wav file using the WavPad Free application.

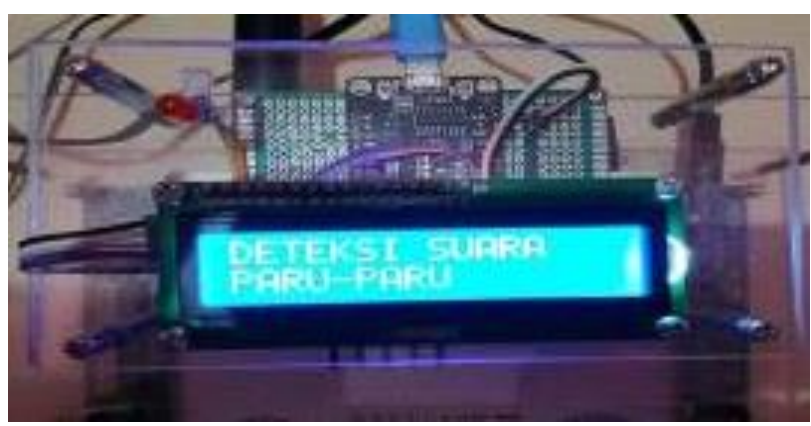

Figure 6 Display on LCD

\subsection{Experiments}

Table 2 Patient data

\begin{tabular}{|c|c|c|c|c|c|}
\hline No. & Name & $\begin{array}{c}\text { Age } \\
(\mathrm{Thn})\end{array}$ & $\begin{array}{c}\text { Height } \\
(\mathrm{Cm})\end{array}$ & $\begin{array}{c}\text { Weight } \\
(\mathrm{Kg})\end{array}$ & $\begin{array}{c}\text { Name } \\
\text { Files }\end{array}$ \\
\hline 1. & $\begin{array}{c}\text { Patient 1 } \\
\text { (Tika) }\end{array}$ & $\begin{array}{c}21 \\
\text { Years } \\
\text { old }\end{array}$ & 150 & 46 & $\begin{array}{c}\text { Data } \\
\text { Pasien 1 } \\
\text { wav }\end{array}$ \\
\hline 2. & $\begin{array}{c}\text { Patient 2 } \\
\text { (Nenty) }\end{array}$ & $\begin{array}{c}20 \\
\text { Years } \\
\text { old }\end{array}$ & 155 & 68 & $\begin{array}{c}\text { Data } \\
\text { Pasien 2 } \\
\text {.wav }\end{array}$ \\
\hline 3. & $\begin{array}{c}\text { Patient 3 } \\
\text { (Alvin) }\end{array}$ & $\begin{array}{c}22 \\
\text { Years } \\
\text { old }\end{array}$ & 184 & 118 & $\begin{array}{c}\text { Data } \\
\text { Pasien 3 } \\
\text {.wav }\end{array}$ \\
\hline 4. & $\begin{array}{c}\text { Patient 4 } \\
\text { (Agus) }\end{array}$ & $\begin{array}{c}25 \\
\text { Years } \\
\text { old }\end{array}$ & 176 & 70 & $\begin{array}{c}\text { Data } \\
\text { Pasien 4 } \\
\text {.wav }\end{array}$ \\
\hline 5. & $\begin{array}{c}\text { Patient 5 } \\
\text { (Fabio) }\end{array}$ & $\begin{array}{c}11 \\
\text { Years } \\
\text { old }\end{array}$ & 140 & 40 & $\begin{array}{c}\text { Data } \\
\text { Pasien 5 } \\
\text {.wav }\end{array}$ \\
\hline 6. & $\begin{array}{c}\text { Patient 6 } \\
\text { (Suryani) }\end{array}$ & $\begin{array}{c}57 \\
\text { Years } \\
\text { old }\end{array}$ & 152 & 55 & $\begin{array}{c}\text { Data } \\
\text { Pasien 6 } \\
\text { wav }\end{array}$ \\
\hline
\end{tabular}
The

The proposed device was tested to some volunteers.

Data of the volunteers are presented in Table 2. There were 6 volunteers consist of female and male age 11-57 years old with the height 140-184 and the weight 40-118 $\mathrm{kg}$. The files data is stored in .wav format that is labeled as shown in Table 2 .

\section{Results of Direct Testing on Women Aged 21 Years}

From the results of direct examination on the patient 1 in Figure 7, it can be seen that the lung sounds in this patient have a duration (time) during the inspiration and expiration process where the expiration process is longer than the inspiratory process. The lung sound in this patient has a high pitch, while the frequency of the process of inspiration and expiration is the same, which is $1000 \mathrm{~Hz}$. By looking at the results of the analysis of the three methods in Figure 7 (b), it can be said that the lung sound of patient 1 can be classified as normal tracheal lung sound.

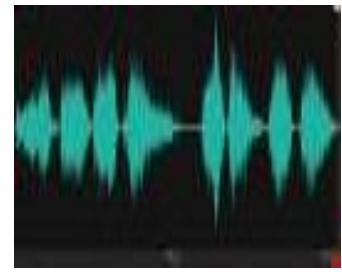

(a)

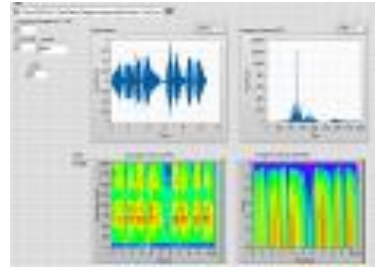

(b)
Figure 7 Results of Patient 1 (a) Smartphones, (b) Front Panel

\section{Direct Testing Results on 20 Years Old Woman}

A graphic display of the pulmonary sound possess of a 20 year old female patient is presented in Figure 8 . From the results of the interpretation of lung sounds, it can be classified as normal bronchovesicular lung sounds. By looking at the absence of time lag during the process of taking patterns from inspiration to expiration which are not visible. Inspirational and expiratory sound patterns with a fairly weak tone with a frequency of 250 HZ.

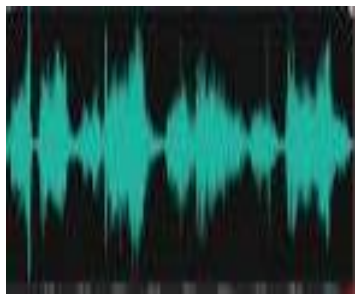

(a)

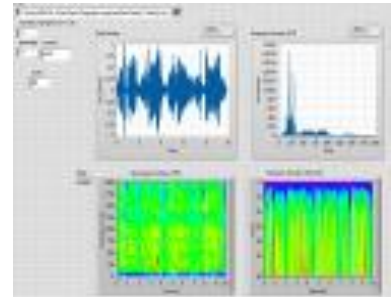

(b)
Figure 8 Results of Patient 2 (a) Smartphones, (b) Front Panel

\section{Direct Testing Results on 22 Years Old Male}

From the results of the patient 3 shown in Figure 9, it can be seen that during the expiration process, the duration is longer or in other word longer than during the inspiration process. This time the patient also has a very high pitch. Then, the frequency of the process of inspiration and expiration looks the same, namely 1750 Hz. From the results of the graphic displayed in Figure 9 above, it can be seen and analyzed that the lung sounds in this patient can be classified as normal Tracheal.

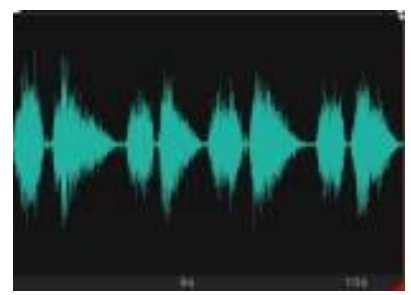

(a)

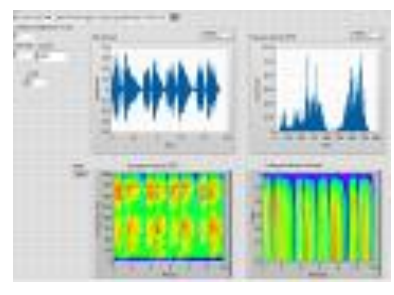

(b)
Figure 9 Results of Patient 3 (a) Smartphones, (b) Front Panel 


\section{Direct Testing Results on Male Age 25 Years}

By looking at the graphic display in Figure 10, it can be concluded that in the inspiratory and expiratory pulmonary sound pattern of this patient, it can be seen that the expiration process is longer than the inspiratory pattern. The lung sound that this patient has shows a high pitch. Then, it can be seen in the STFT Scalogram graphic display in Figure 10 (b) that the inspiration process has a frequency of $750 \mathrm{~Hz}$, while the expiration process has a frequency of $1000 \mathrm{~Hz}$. Thus, the lung sound in this patient is classified as normal Tracheal lung sound

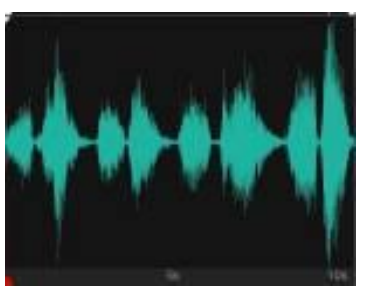

(a)

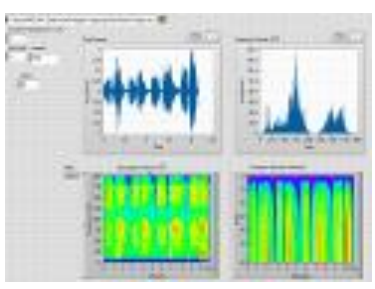

(b)
Figure 10 Results of Patient 4 (a) Smartphones, (b) Front Panel

\section{Results of Direct Testing on 11 Years Old Male}

From the graphic display in Figure 11, it can be seen that this 11 year old male patient has normal lung sounds. By looking at the results of the inspirational and expiratory patterns, the pitch is quite hard and high pitched. Then, the duration of inspiration and expiration is almost the same, i.e., when the inspiration process, it has a frequency of $250 \mathrm{~Hz}$ and during the expiration process it has a frequency of $500 \mathrm{~Hz}$. As well as, in the process between inspiration and expiration, there is a lag (time). This sound is similar to bronchovesicular lung sounds, however, due to the difference, namely the lag (time) between the process of inspiration and expiration, this lung sound can be classified as normal bronchial lung sound.

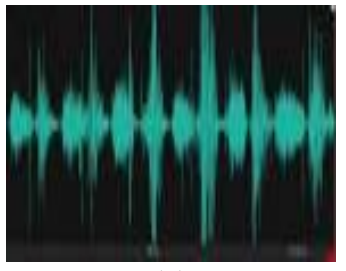

(a)

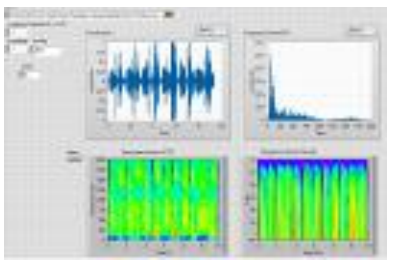

(b)
Figure 11 Results of Patient 5 (a) Smartphones, (b) Front Panel

\section{Results of Direct Testing on a Female Age of 57 Years}

It can be seen in the Figure 12, that is a graphic display of lung sounds owned by a woman aged 57 years. By looking at the sound pattern of the lungs during the inspiration and expiration process, this patient has a high pitch. Then, by looking at the graphic display in Figure 12, it can be seen that the expiration process has a longer duration (time) than the inspiration process, i.e., the expiration process has a frequency of $1250 \mathrm{~Hz}$ while the inspiration process has a frequency of $750 \mathrm{~Hz}$. Thus, it can be said that the lung sound in this patient is classified as normal tracheal lung sound

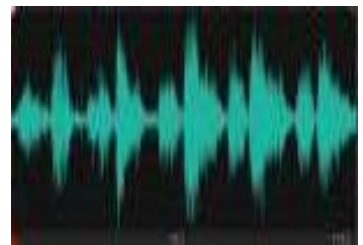

(a)

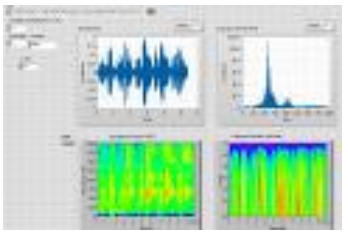

(b)
Figure 12 Results of Patient 6 (a) Smartphones, (b) Front Panel

\section{CONCLUSSION}

Due to the corona pandemic, this device cannot be tested to sickness patient that shows disorder lung sounds. However, this device has been successful to detects all of the 6 patients as the volunteers of this research. The detection of lung sounds using DSP TMS320C6416T signal that has been captured by a modified microscope electrets condenser microphone has been successful to be converted into the digital signal that can be read in a computer. The signal has been successful to be saved in the form of .wav format, which then, can be transferred to the smart phones via wifi communication in the NodeMCU ESP8266. The output of the signal sounds can be visualized well in the smart phones.

\section{REFERENCES}

[1] R. Invernizzi, C. M. Lloyd, and P. L. Molyneaux, "Respiratory microbiome and epithelial interactions shape immunity in the lungs," Immunology. 2020, doi: 10.1111/imm.13195.

[2] J. Wang, M. Hossain, A. Thanabalasuriar, M. Gunzer, C. Meininger, and P. Kubes, "Visualizing the function and fate of neutrophils in sterile injury and repair," Science (80-. )., 2017, doi: 10.1126/science.aam9690.

[3] M. Ackermann et al., "Pulmonary Vascular Endothelialitis, Thrombosis, and Angiogenesis in Covid-19," N. Engl. J. Med., 2020, doi: 10.1056/nejmoa2015432.

[4] H. Huang, D. Yang, X. Yang, Y. Lei, and Y. Chen, "Portable multifunctional electronic stethoscope," in Proceedings of 2019 IEEE 3rd Information Technology, Networking, Electronic and Automation Control Conference, ITNEC 2019, 2019, doi: 10.1109/ITNEC.2019.8729172.

[5] A. Manfredi et al., "Diagnostic accuracy of a velcro sound detector (VECTOR) for interstitial lung disease in rheumatoid arthritis patients: The InSPIRAtE validation study (INterStitial pneumonia in rheumatoid ArThritis with an electronic device)," BMC Pulm. Med., 2019, doi: 
10.1186/s 12890-019-0875-X.

[6] O. Ur-Rehman and N. Zivic, "Wireless communications," in Signals and Communication Technology, 2018.

[7] N. L. Husni, S. Sitangsu, S. Rasyad, F. Damsi, and A. Silvia, "Real Time Garbage Bin Capacity Monitoring," Comput. Eng. Appl. J., vol. 9, no. 2, pp. 127-133, 2020.

[8] N. L. Husni, E. Prihatini, and A. Silvia, "Garbage Monitoring and Warning System," 3rd ICECOS, 2019.

[9] Nyayu Latifah Husni et al, "Garbage Box (G-Box)
Designing and Monitoring," ITC CSCC Conf., pp. 5-8, 2019.

[10] D. A. Pratama, N. L. Husni, E. Prihatini, S. Muslimin, and O. F. Homzah, "Implementation of DSK TMS320C6416T Module in Modified Stethoscope for Lung Sound Detection," J. Phys. Conf. Ser., vol. 1500, no. 1, 2020, doi: 10.1088/1742-6596/1500/1/012012.

[11] B. M. Rocha et al., "A respiratory sound database for the development of automated classification," in IFMBE Proceedings, 2018, doi: 10.1007/978981-10-7419-6_6. 